\title{
PATHOGENICITY OF ENTOMOPATHOGENIC FUNGI FROM LEBANESE SOILS AGAINST APHIDS, WHITEFLY AND NON-TARGET BENEFICIAL INSECTS
}

\author{
IBRAHIM L. , HAMIEH A., GHANEM H., IBRAHIM S.K.
}

Department of Crop Protection, Lebanese University, Beirut, Lebanon

*Corresponding Author: Email- ludmilla41@yahoo.co.uk

Received: December 20, 2011; Accepted: December 28, 2011

\begin{abstract}
Three newly isolated and two existing isolates of $M$. anisopliae and B. bassiana were tested against aphids, whiteflies and beneficials, individually and with chitin synthesis inhibitor. Hundred percent of aphids have died of fungal treatments 7 days post inoculation, but number of individuals that developed mycosis varied depending on the isolate used. Whiteflies, however, were slightly more resistant. All tested isolates appeared to be fast killing fungi requiring only one or two days for reducing aphid population by half and needing 4 to 6 days for $50 \%$ of whiteflies to succumb to the disease. Both, aphid and whitefly, mortalities increased with increasing dose. The estimated $\mathrm{LC}_{50}$ values against $M$. persicae were $10^{3.88}$ and $10^{4.75}$ conidia $\mathrm{ml}^{-1}$, respectively. These results were comparable with values obtained for the same isolates tested against whitefly Bemisia tabaci. Hundred precent of parasitized aphids by whitefly parasitoid demonstrated the emergence hole in the controls and in the individuals treated with new M. anisopliae isolate and $87 \%$ of emergence holes in the individuals treated with new $B$. bassiana. Exposure of mealybug predator to new isolates resulted in high mortalities. Native $B$. bassiana isolate in combination with diflubenzuron significantly reduced population of 1stinstar larvae of whiteflies under greenhouse conditions 14 days post treatment.
\end{abstract}

Key Words- Entomopathogenic fungi, Biological control, Metarhizium anisopliae, Beauveria bassiana, aphids, whiteflies Cryptolaemus montrouzieri, Encarsia Formosa

\section{Introduction}

Vegetable production in greenhouses is very common in Lebanon, however, this allows for a rapid spread of diseases and pests such as green peach-potato aphids Myzus persicae (Sulzer) (Hemiptera: Aphididae) and whiteflies Bemisia tabaci (Genaddius) (Hemiptera: Aleyrodidae). In addition to their direct involvement as virus transmitters, aphids and whiteflies have large reproductive rates and their wide range of host plants means that they are difficult to control. Selective aphicides have been used to reduce populations to below damage threshold levels [1]. If they are to be used as sole control agents for pests that have several generations during a crop cycle, they will have to be applied repeatedly because of the reproductive capacity of the pest. Intensive crop production and extensive use of harmful synthetic chemical pesticides creates numerous socio-economic problems worldwide. Probably the most profound is the harm the pesticides are doing to humans and the environment. In addition, there are increasing reports of pesticide resistance in pest populations. For example, more than 20 aphid species including $M$. persicae [2,3] have developed resistance to a number of carbamate, pyrethroid and organophosphate based insecticides. Exports of Lebanese produce could also be affected especially to countries which have stringent measures to monitor residues on produce. There is an urgent need to develop more benign agents and strategies for the control of crop pests. Recent EU legislation (Directive 128/2009/EC) makes it obligatory on EU Member States to implement integrated pest management (IPM) programs with preference being given to the use of nonchemical control agents for pest control. Entomopathogenic fungi such as Beauveria bassiana (Balsamo) Vuillemin (Ascomycota: Hypocreales) and Metarhizium anisopliae (Metschnikof) Sorokin (Ascomycota: Hypocreales) offer an environmentally friendly alternative to chemical pesticides. These fungi are natural, can be easily formulated, less toxic to mammalian, leave no harmful residues [4] and problems with resistance are less likely to occur [5]. M. anisopliae and $B$. bassiana have a wide host range $[6,7]$ are widely distributed in all regions of the world and can be easily isolated from insects, soil and phylloplanes of hedgerow vegetation [8]. Several products based on strains of Lecanicillium sp. [9], B. bassiana, M. anisopliae and Paecilomyces have been reported to control a range of pests including aphids and whiteflies $[6,7,10,11]$.

Today, biological control has become a key component of crop protection worldwide and relies on the introduction of exotic or naturally occurring biological control agents (BCAs) which will permanently suppress pests and persist in the environment. Bruck [12] suggested that success in application of BCAs in nature has close relationship with their related biological systems especially with their ecological niche. And when placed into the system with ecological constrains 
the BCA's performance would usually be inconsistent [13]. Based on other reports, produced inocula on naturally infected insects is more virulent and effective than harvested inoculum from axenic culture media [14]. This is important especially for mass production of Metarhizium and other entomopathogens which are used as mycoinsecticides. A suspected reason for decrease in pathogen's virulence (attenuation) is ingredients of culture media $[14,15]$. In order to find a robust, stable and virulent inoculum which is efficacious in pest control under a wide range of environments, it is important to continuously search for new entomopathogens with more desirable attributes.

In addition, there have been some concerns about the indirect effects of newly introduced or existing BCAs on local communities and non-target species. This concern can be evaluated by assessing the effects of new populations on non-target and beneficial insects. However, up-to-date very few studies were dealt with the effects of $B$. bassiana and $M$. anisopliae on nontarget organisms $[16,17]$. Also, when implementing an integrated management programme, growers must concern themselves with many production hurdles such as presence of pests, plant pathogens, weeds and their prophylactic measures. Because of this, there is a high probability that concerned crop will also be treated with one or more of a number of insecticides, acaricides, fungicides or herbicides at some point during the production cycle. An understanding of the potential effects of these chemicals on $B$. bassiana and $M$. anisopliae is critical to the successful integration of the new microbial control agents. Recently, diflubenzuron (Dimilin SC48), a chitin synthesis inhibitor has been used [18] to suppress cedar webspinning sawfly Cephalcia tannourinensis pest population in cedar forests of Lebanon. Pesticides which kill the insects by inhibiting the chitin synthesis are found in the group of insect growth regulators such as buprofezin and diflubenzuron. As chitin is one of the main cuticle components, a reduced level of chitin might increase the efficacy of entomopathogenic fungi. Therefore, a possible synergism between $M$. anisopliae or $B$. bassiana should be investigated.

The aims of this study were to determine the pathogenicity of newly isolated from Lebanese soils and exotic isolates of $M$. anisopliae and $B$. bassiana against two major crop pests, M. persicae (peach-potato aphid) and B. tabaci (whitefly) and their effect on two beneficial, non-target insects, Cryptolaemus montrouzieri Mulsant (Coleoptera: Coccinellidae) which feeds on mealybugs and Encarsia formosa Gahan (Hymenoptera: Aphelinidae) whitefly parasitoid. The effect of a combined treatment of the entomopathogens and chitin synthesis inhibitor diflubenzuron on whiteflies was investigated under laboratory and greenhouse environments.

For full articles, the manuscript, written in English, should not exceed 30 pages in length (ca. 15 printed pages) and for mini-reviews a maximum of 40 pages in length (ca. 20 printed pages). The manuscript should be typed in double-spacing throughout on A-4 or American quarto paper. Dot matrix print or any print that is difficult to read is unacceptable. Soft copies of the manuscript must accompany the original and should be sent to the Editor-in-Chief at his address. All pages should be numbered. Abbreviations should be defined the first time they are used in the manuscript and a list of abbreviations used should also be provided.

\section{Experimental \\ Soil collection}

Thirty five soil samples from the upper $10 \mathrm{~cm}$ of fallow and cultivated agricultural land were collected from different regions of Lebanon (north, central and south). Each soil sample was consisting of 25 cores $(2.5 \times 5 \mathrm{~cm})$ collected from each field in "Z" pattern and bulked together to give approximately $1 \mathrm{~kg}$ of soil. Soil samples were deposited into plastic bags, tagged and stored in a plastic container at $4 \pm 1^{\circ} \mathrm{C}$ until processing. Before use, samples were thoroughly mixed and passed through a $0.4 \mathrm{~mm}$ mesh sieve breaking soil lumps and separating any litter.

\section{Fungal isolation}

Three methods for the isolation of the fungi were used. This provided the opportunity to compare which of these methods were more efficient, cost effective and most reproducible. The first method entailed isolation using selective medium as outlined by Rath et al. [19]. Briefly, moist unsterilized soil equivalent to $20 \mathrm{~g}$ was added to 200 $\mathrm{ml}$ of sterile Ringer's solution (made in the lab) in a 500$\mathrm{ml}$ Erlenmeyer flask. The suspension was shaken at 150 rpm for $30 \mathrm{~min}$ on an orbital shaker then $0.1 \mathrm{ml}$ of neat, 1:10 and1:100 dilutions in sterile distilled water were spread-plated onto Sabouraud Dextrose Agar (SDA) amended with Streptomycin Sulfate $\left(20 \mu \mathrm{g} \mathrm{I}^{-1}\right)$. There were three replicates for each dilution. Plates were sealed, labelled, incubated at $23 \pm 2^{\circ} \mathrm{C}$ in the dark and then examined 12, 24, 48, 72, 96 and $120 \mathrm{~h}$ post plating. The second method entailed isolation of the fungi on Veen's semi-selective medium [20]. The third method was unamended (i.e. antibiotic or fungicide free) SDA medium only. As soon as fungal colonies were observed, these were transferred to fresh SDA plates and incubated at $23 \pm 2^{\circ} \mathrm{C}$ in the dark for further 21 days. Contaminated cultures were transferred to fresh media until they were totally free of competing microbes. The fungal isolates were then kept at $5 \pm 1^{\circ} \mathrm{C}$.

\section{Fungal identification}

To facilitate rapid sporulation, isolates were transferred to water agar and incubated at $26 \pm 2^{\circ} \mathrm{C}$ for three days. Following spore formation, conidia were examined using light microscopy. Several isolates produced a white mycelium but did not produced conidia and for that reason were not identified. A range of isolates such as $M$. anisopliae , Aspergillus spp, B. bassiana, Mucor spp and Fusarium spp were identified at lower 60x magnification. To further characterise the isolates of our interest, namely $M$. anisopliae and B. bassiana, conidia or germlings of 
single spore cultures were suspended in $0.03 \%$ aqueous Tween 80 suspension, fixed with lactophenol cotton blue and observed under light microscope with phase optics at 400x magnification.

Identification of fungal isolates was done as described by the Manual of Pathogenic Fungi and Bacteria, International Mycological Institute (IMI) [21] and Entomopathogenic Fungal Identification Keys [22].

\section{Maintenance and storage of fungal cultures}

Background and origin of isolates used in these studies are presented in Table 1. Long term storage of each isolate was achieved by freezing conidia in $10 \%$ w.w. Glycerol (BDH). When required conidia were re-hydrated by suspending in a small volume of sterile water, placed on SDA and incubated at $23 \pm 2^{\circ} \mathrm{C}$ in the dark for 14 days. Following incubation conidia were scraped from sporulating colonies and suspended in $0.03 \%$ Tween 80 solution. The resulting conidial suspension was then filtered three times through three layers of sterile cheese cloth in order to remove any hyphal fragments.

\section{Bioassays \\ Myzus persicae (green peach-potato aphids)}

Mixed field-collected populations of $M$. persicae were obtained from hot pepper plants (Capsicum frutescens $\mathrm{L}$ ) grown in an open field and placed into ventilated plastic boxes containing leaves of hot pepper plants and monitored for symptoms of natural fungal infection or parasitism. Only healthy individuals were used in pathogenicity assays.

Conidial suspensions $\left(1.0 \times 10^{7}\right.$ conidia $\left.\mathrm{ml}^{1}\right)$ of all isolates used were prepared using the same procedure described in above section. For each treatment, a $50 \mathrm{~mm}$ diam leaf disc was cut out of a healthy lettuce leaf and dipped into $5 \mathrm{ml}$ of conidial suspension for $10 \mathrm{sec}$ and the excess suspension removed by placing the discs on sterile filter paper for $10 \mathrm{~min}$. The disc was then placed on a fresh moist filter paper in a plastic Petri dish. Twenty healthy aphids were placed on the treated leaf disc and incubated at $23^{\circ} \pm 2^{\circ} \mathrm{C}$ with a $16: 8 \mathrm{~h}$ (Light:Dark) photoperiod. Controls consisted of discs immersed in $0.03 \%$ Tween 80 only. There were 4 replicates per treatment. All Petri dishes were inspected twice daily. The number of dead aphids was recorded over a period of 7 days. Cadavers were transferred to Petri dishes lined with moist tissue paper to encourage fungal growth and sporulation in order to confirm that death was due to fungal infection.

Since native isolates LIB1 and LIM1 were equally or more pathogenic than exogenous isolates towards aphids, they were selected for $L_{50}$ and $L T_{50}$ studies using the same inoculation procedures as described above at concentrations of $10^{4}-10^{8}$ conidia $\mathrm{ml}^{-1}$. Mortalities for $\mathrm{LC}_{50}$ and $\mathrm{LT}_{50}$ were assessed 9 days post inoculation.

\section{Bemisia tabaci (whitefly)}

For whitefly $B$. tabaci inoculation procedure was obtained by transferring whitefly adults from infested plants in a greenhouse into cages with rearing potato plants (30 adults per cage). Thereafter, the whiteflies were allowed to lay eggs for 48 hours under greenhouse conditions and then removed. Number of eggs was recorded before inoculation. Subsequently, conidial suspension $\left(10^{7} \mathrm{ml}^{-1}\right)$ was applied to eggs with a commercial hand sprayer at a volume of $15 \mathrm{ml}$ per plant. Marked leaflets of potato leaves were left to dry in order to prevent saprophyte growth in the droplets, then they were detached from each plant and placed in boxes lined with moist filter paper and incubated at $23 \pm 2{ }^{\circ} \mathrm{C}$ in the dark. Control plants were sprayed with $0.003 \%$ Tween 80 solution only. One replicate comprised of 5 leaflets detached from each plant. There were 10 plants for each treatment. Laval mortality was recorded daily over a period of 7 days. The number of eggs and larvae were assessed using binocular. If larvae of whiteflies were opaque or whitegreenish and shiny with visible honeydew droplets appearing on the excretions they were regarded as alive. Larvae were regarded dead if their bodies were brownish mat and shrivelled.

$\mathrm{LC}_{50}$ and $\mathrm{LT}_{50}$ values were determined using isolates LIB1 and LIM1 at concentrations of $10^{4}-10^{8}$ conidia ml-1 and the same inoculation procedures as described above. Mortalities for $\mathrm{LC}_{50}$ and $\mathrm{LT}_{50}$ were assessed 9 days post inoculation.

\section{Encarsia formosa (whitefly parasitoid)}

Parasitized adults and different instars nymphs of $M$. persicae were collected from a field under $C$. frutescens and taken to the laboratory. When emerged, parasitic wasps were slide-mount for species identification. Identified as Encarsia formosa (Dr L. Khoury, personal communication), the parasitoids were introduced to a population of $3^{\text {rd }}$ and $4^{\text {th }}$ instars nymphs of $M$. persicae. To determine susceptibility level of $E$. formosa to $M$. anisopliae and $B$. bassiana each aphid individual was examined under a microscope to make sure that it carried a larva of $E$. formosa. Only parasitized aphids were used in this bioassay. Twenty parasitized aphids were then inoculated with conidial suspensions of LIM1 and LIB1 using the same inoculation procedure as described in the section $M$. persicae. Control aphids were treated with $0.03 \%$ Tween 80 suspension only. Each treatment consisted of 4 replicates. Emergence of $E$. formosa in each treatment was recorded daily for a period of 9 days. After parasitoids have immerged, aphid mummies were checked for fungal growth.

\section{Cryptolaemus montrouzieri (mealybug ladybird)}

Mealybug ladybird is a predator of mealybugs, but when no mealybugs are available Cryptolaemus will also feed on aphids, scale, mites, thrips, whitefly, and other soft bodied insects. Mix-aged larvae of $C$. montrouzieri in this study were collected mainly from the vineyards and citrus orchards infested with $M$. persicae and scale insects, respectively. Only healthy larvae were used in this study. Infested with $M$. persicae vine leaves were each sprayed with $1 \mathrm{ml}$ of LIM1 and LIB1 at 1.0×107 conidia ml-1 and placed into a Petri dish lined with moist filter paper. Five larvae were then introduced to each Petri dish and 
incubated at room temperature. Ten replicate dishes were prepared for each treatment. Controls consisted of vine leaves treated with $0.03 \%$ Tween 80 only. Observations of treatments were made daily and larval mortality recorded for a period of 9 days. As with the aphids, dead larvae were removed and checked for fungal growth and sporulation.

\section{Compatibility of entomopathogenic fungi with insect growth regulator}

Investigations on the effect of combinatory insect growth regulator-fungus treatments on whitefly populations were carried out on detached potato leaves at $23^{\circ} \pm 2^{\circ} \mathrm{C} \mathrm{C}$, in the dark and $100 \%$ humidity in the laboratory and on the whole plants in a greenhouse with fluctuating temperatures, humidity and natural day:night lights. Infestation with greenhouse whiteflies and application of treatments were carried out as described in section $B$. tabaci. Treatments consisted of suspension ( $10^{7}$ conidia $\mathrm{ml}^{-1}$ of LIB1 and LIM1) or conidial suspension combined with recommended dose of $0.4 \mathrm{ml} / \mathrm{L}$ of diflubenzuron. Control plants were sprayed with $0.03 \%$ Tween 80 solution only. There were 5 leaflets (replicate) from each of 10 plants per treatment. Mortality was recorded every two days for two weeks.

\section{Statistical analysis}

Average percentages of mortality were obtained and normalized through angular transformation after correcting for control mortality [23]. Angular values of mortality were then subjected to analysis of variance (ANOVA) and means were separated by Tukey's (HSD) test at $P=0.05$ using the ANOVA procedure of SAS [24]. Fifty percent lethal time and lethal concentration ( $L T_{50}$ and $\mathrm{LC}_{50}$, respectively) were estimated by fitting mortality data to Weibull survival distribution [25] using the LIFEREG procedure of SAS. The values were then subjected to ANOVA and means separated using Tukey's test.

\section{Results \\ Fungal isolation}

Although a large number of soil samples were screened, only 4 fungal strains of interest were isolated (Table 2). Three strains of $M$. anisopliae were isolated from soil of a private organic garden (Dalhoun, Central Lebanon). One strain of $B$. bassiana species was recovered from soil of fallow land (Wadi Dalhoun, Central Lebanon).

\section{Fungal identification}

All key diagnostic characters $[21,22]$ were present in the isolates of $M$. anisopliae and $B$. bassiana. Cultures of $M$. anisopliae appeared dark herbage to light green with powdery and finally crustose surface. Cylindrical conidia emerged in typical for this species chains. B. bassiana cultures, in contrast, became visible as powdery, white or pale yellow mycelia forming clustered globular, ellipsoidal or flask-shaped conidia. At higher magnifications (1000x) distinct size differences were observed based on c. 25 measurements per isolate. Conidial size of $M$. anisopliae ranged from 3.5 to $6.4 \mu \mathrm{m}$ long, whereas size of $B$. bassiana conidia varied between $1.5 \mu \mathrm{m}$ to $2.7 \mu \mathrm{m}$ in length. These descriptions agreed with those given by IMI $[21,22,26]$.

\section{Bioassays \\ Myzus persicae}

Six fungal isolates were evaluated for their potential to control $M$. persicae (Tab.2). Although all isolates tested in this assay caused $100 \%$ mortality 7 days post inoculation, the investigations demonstrated significant differences in the virulence of these isolates concerning the cumulative mortality after two days post-treatment $\left(F_{5,23}=31.80 ; P\right.$ $<0.001)$. For example, high mortalities of $80 \%, 81 \%$ and $87 \%$ were observed for native $B$. bassiana (LIB1) isolate and for exotic isolates of $B$. bassiana (Botanigard $(\mathrm{R})$ and M. anisopliae (V275), respectively. The ability to cause mycosis 2 days post treatment was greater for native LIB1 isolate $\left(F_{5,23}=5.28 ; \quad P=0.004\right)$ in comparison to exotic BotaniGard $\AA$ and V275 isolates. Also, all native strains of $M$. anisopliae (LIM1, LIM2 and LIM3) and B. bassiana (LIB1) exhibited higher percentage (80\%) mycosis $\left(F_{5,23}=21.38 ; \quad P<0.001\right)$ developed on aphid's cadavers 7 days post treatment (Tab 2).

Significant variations between the times required for each isolate to acquire $50 \%$ death were observed 7 days post inoculation $\left(\mathrm{F}_{5,23}=41.63 ; P<0.001\right)$ (Tab. 2). However, all isolates used in this test appeared to be fast killing fungi requiring one or two days for reducing aphid population by half.

$\mathrm{LC}_{50}$ and $\mathrm{LT}_{50}$ studies (Tab. 4) revealed dose-dependent mortality of $M$. persicae. Estimated LC $\mathrm{C}_{50}$ for LIM1 isolate with value of $10^{4.75}$ conidia $\mathrm{ml}^{-1}$ was significantly higher $\left(F_{1,7}=9.58 ; \quad P=0.021\right)$ than that for LIB1 (Tab. 4). The respective estimated $L T_{50}$ values of LIM1 and LIB1 for $M$. persicae adults at $10^{5}$ conidia $\mathrm{ml}^{-1}$ were 6.8 and 5.6 days, respectively (Tab.4). Increase of conidial concentration by a 1000 fold significantly $\left(F_{3,31}=108.48 ; \quad P<0.001\right)$ reduced aphid population by $50 \%$ in less than one day.

\section{Bemisia tabaci}

Six fungal isolates were also evaluated for their potential to control $1^{\text {st }}$ instar larvae of whiteflies. The investigations demonstrated significant differences in the virulence of the isolates concerning the cumulative mortality after 7 days post treatment $\left(F_{5,59}=79.70 ; \quad P<0.001\right)$ and between the times required for each isolate to acquire $50 \%$ death $\left(F_{5,59}=45.96 ; \quad P<0.001\right)$ (Tab. 3). The highest mortality was observed for $B$. bassiana (BotaniGard $($ ) ) strain causing death in $50 \%$ of whiteflies within 3.4 days (Tab. 3) and in $96.5 \%$ of whiteflies in 7 days. In comparison to the native isolates of $M$. anisopliae, LIB1 isolate was the only isolate that killed more than $30 \%$ of larvae within 3 days, $50 \%$ within 4.5 days and caused mortality in $88 \%$ of larvae in 7 days. Mortalities of Bemisia 1st instar larvae due to native $M$. anisopliae isolates ranged between $63 \%$ and $70 \%$. Dead larvae appeared to be brown and shrivelled in appearance. 
Results of $\mathrm{LC}_{50}$ and $\mathrm{LT}_{50}$ studies were comparable with values obtained for the same isolates tested against $M$. persicae. Fifty percent of Bemisia population were killed by Metarhizium at concentration of around 105.75 conidia $\mathrm{ml}^{-1}$ and by Beauveria at significantly $\left(F_{1,19}=113.12 ; P<\right.$ 0.001 ) lower concentration of $10^{4.12}$ conidia $\mathrm{ml}^{-1}$ (Tab. 4) 9 days post treatment. On the other hand, almost 8 days were needed for half of the larval population to succumb to the disease at $10^{5}$ conidia $\mathrm{ml}^{-1}$. With increasing conidial concentration $\mathrm{LT}_{50}$ values were significantly decreasing for both LIM1 $\left(F_{3,31}=108.49 ; P<0.001\right)$ and LIB1 $\left(F_{3,79}\right.$ $=210.90 ; P<0.001)($ Tab. 4) isolates.

\section{Encarsia formosa (whitefly parasitoid)}

Hundred precent of parasitised aphids demonstrated the emergence hole in the controls and in the individuals treated with LIM1. No mycelial growth or sporulation was observed on aphid mummies (Fig. 1). Furthermore, sporulation of LIB1 isolate was observed on $14.2 \%$ of aphids that have died at advanced stage of parasitism. Also, the emergence hole was absent in those aphids that exhibited external fungal growth. However, no fungal growth of LIB1 on the dead parasitoids was observed.

\section{Cryptolaemus montrouzieri (mealybug ladybird)}

Significant differences in mortalities between treatments were noted $\left(F_{1,19}=28.71 ; \quad P<0.001\right)$ (Fig.2). More mealybug ladybirds have died from $B$. bassiana (LIB1) infection than from $M$. anisopliae (LIM1). Also, more cadavers developed mycosis (16.9\%) previously treated with Beauveria in comparison to those treated with Metazhizium (7.7\%) $\left(F_{1,19}=235.63 ; \quad P<0.001\right)$. No fungal growth was observed on the dead larvae in controls.

\section{Compatibility of entomopathogenic fungi with insect growth regulators}

Results presented in Fig. 3 show that effectiveness of treatments (biological/LIM1 and LIB1, chemical/diflubenzuron or combination of both) differ significantly under the laboratory $\left(F_{4,49}=12.53 ; \quad P<\right.$ $0.001)$ and greenhouse $\left(F_{4,49}=102,3 ; \quad P<0.001\right)$ conditions. Eighty one percent of whitefly larvae in the laboratory died from diflubenzuron treatment, $84 \%$ from $B$ bassiana infection and $87 \%$ from $B$. bassiana/diflubenzuron combinatory treatment. The larval susceptibility to LIM1 and LIM1/diflubenzuron were significantly lower $(P<0.05)$ resulting in $52 \%$ and $56 \%$ mortalities, respectively, in comparison to other treatments. Addition of fungal pathogen to the growth regulator did not significantly increase or decrease larval mortalities. In the greenhouse, however, LIB1/ diflubenzuron combination showed significantly higher effect on larval mortalities (89\%) in comparison to the other treatments $((P<0.05)($ Fig. 3)).

\section{Discussion}

Entomopathogenic fungi have been observed to cause mortality in pest populations and thus investigated for their potential as biological control agents $[6,7,27]$ or successfully developed as biocontrol agents against a number of different pests, including aphids $[28,29]$. Traditionally, entomopathogenic fungi have been applied (usually as conidia) to the cropping system using an inundative or inoculative biological control strategy [30]. These approaches, however, do not exploit the indigenous reservoir of fungi that is already present in the cropping system. Therefore, knowledge of the community of natural enemies in the agro-ecosystem as well as the effect of the agronomical practices on these organisms is essential. In current study, insect pathogenic strains of $M$. anisopliae and $B$. bassiana together with many other nonentomopathogenic soil fungi such as $A$. niger, $A$. flavus, Penicillium spp., Mucor spp. and Fusarium spp. were isolated from Lebanese soils. Abdo et al.[31] have also reported the isolation of $B$. bassiana strains from third instars larvae of Cephalcia tannourinensis Chevin (Hymenoptera: Pamphiliidae) and soils under the trees of Tannourine-Hadath El-Jebbeh cedar forest in Lebanon. Although fungal strains of $A$. niger, A. flavus, Penicillium spp., Mucor spp. and Fusarium spp. have been previously observed and isolated from other insects and soils with significantly frequent incidence rates [32], they were not strict entomopathogenic organisms but rather plant pathogens that cause undesirable plant diseases [33] or simply opportunistic fungi that cannot cause epizootics in insect's population [32,34]. For these reasons they were not tested against target pests in our study.

Suggested medium for isolation of Metarhizium is often called Veens' semiselective medium. Although shown effective in our assays, this medium was proven to be relatively expensive and time-consuming in preparation. Also, this medium was found to be inhibitory to $M$. anisopliae [35]. Therefore, dodine and cyclohexamide was omitted and SDA was amended with streptomycin sulfate antibiotic only. Twenty $\mu \mathrm{g}$ of antibiotic added to one liter of SDA was found to be adequate amount to suppress rapid growth of bacteria and other antagonistic fungi. Surprisingly, however, SDA alone was also shown to be equally straightforward, inexpensive and reliable media for isolation of Metarhizium and Beauveria from unsterilized samples in our laboratory.

All isolates tested in this study against $M$. persicae were identified as highly pathogenic. However, higher level of deaths due to mycoses as evidenced by sporulation on the surface of aphids' cadavers was noted for native LIM1 and LIB1 rather than for exotic isolates. Self-propagation is potentially useful characteristic since the inoculum produced could further infect pest insect contacting it. Furthermore, the virulence of inocula passaged through a natural host should be maintained [36]. The native Lebanese strain of $B$. bassiana has previously been studied for its efficacy against the 1st larval instars of $C$. tannourinensis [31] causing more than $93 \%$ death at concentration of $4.6 \times 10^{3}$ conidia ${ }^{-1}$. Such high mortality could be attributed to the highly host-specific attributes of this isolate since this strain was originally isolated from $C$. tannourinensis larva. Other studies have similarly shown that isolates derived from the host under evaluation were 
more pathogenic than non-host derived isolates [37]. In the study undertaken here, all four native isolates were isolated from soils of either fallow land or private organic garden and thus hosts were unknown. Butt and coworkers [6] have previously shown that $M$. anisopliae isolates possess useful characteristic of being a broadspectrum mycoinsecticide. Even though these species have a wide host range, they still exhibit specificity within certain insect groups and pests $[6,7]$. Exposure of whiteflies to isolates with exotic background in our study resulted in higher mortalities and more variable $\mathrm{LT}_{50}$ values. Native strains, on the other hand, exhibited shorter $L T_{50}$ values and thus were selected for further investigations against $M$. persicae and $B$. tabaci. Calculated $\mathrm{LC}_{50}$ and $\mathrm{LT}_{50}$ values suggested that $B$. bassiana was more effective against both, $M$. persicae and $B$. tabaci, than $M$. anisopliae. Fifty percent control of both pests was achieved at the concentration of around $10^{4}$ conidia ml-1. However, LIM1 was more effective at lower $10^{5}$ conidia ml-1 against $M$. persicae than at higher concentration of $10^{6}$ conidia $\mathrm{ml}^{-1}$ against $B$. tabaci. In addition, increasing conidial concentration considerably decreased time taken to cause mortalities in $50 \%$ of both pest species. Recent studies also reported a well fit timeconcentration-mortality model of ten $M$. anisopliae isolates against $M$. persicae [38]. Examination of cadavers of dead aphids in our assays indicated that although aphids exposed to the high and low doses of inoculum differed in their incidence of external sporulation; sporulation appeared to be more prolific on insects exposed to the lower doses. These aphids usually exhibited a dense uniform layer of conidia compared to the formation of mycelia with irregular sporulation recorded on aphid cuticles exposed to higher inoculum doses.

Based on the number of mummies and percentage of $E$. formosa emergence holes, effects of $M$. anisopliae (LIM1) on parasitoid mortalities were minimal. Inhibition of fungal development inside parasitized host could be explained by production of fungistatic compounds within the haemocoel of parasitized insects by parasitoid teratocytes [39]. Mummified aphid cadavers in our study also were free from mycilial invasion or conidiation. Similarly, parasitoid tissues inside potato aphid mummies previously parasitized by braconid wasps Aphidius nigripes and infected with Verticillium licanii (Zimm.) were found to be free from the fungus [40]. These findings suggest that $E$. formosa and $M$. anisopliae (LIM1) are compatible and can be used simultaneously to control some pests. However, $22 \%$ of mummified aphid cadavers previously treated with $B$. bassiana (LIB1) did not show emergence holes and $14 \%$ of those were covered with mycelial growth and conidiation. These suggest that either $E$. formosa slightly more susceptible to $B$. bassiana than to $M$. anisopliae or the fungus is more resistant to an immune response of the parasitoid.

In this study, C. montrouzieri was exposed to a low dosage of $M$. anisopliae and $B$. bassiana. Both indigenous isolates resulted in very high mortalities but developed very low signs of mycosis. High mortalities of this predator could be due to starvation. In addition to the immune response [41], potential hosts may also show behavioural resistance (e.g. developed adaptation to detect and consequently avoid contact with pathogens). For example, E. formosa parasitoid is known to detect hosts infected with entomopathogenic fungi within three days of fungal infection [42]. These adaptations are termed 'social immunity' and well-studied in insectsocieties such as ants, termites and some bees which have evolved behavioural mechanisms to prevent disease establishment. However, little $[43,45]$ or contradictory information [46] exists about the ability of non-social insects such as seven-spot ladybird Coccinella septempunctata L. (Coleoptera: Coccinellidae) to avoid pathogens. Therefore, more studies should be conducted to demonstrate an ability of aphid predators or parasitoids to detect and avoid the pathogen that causes natural diseases. This ability will, certainly, increase fitness of beneficial insects. Having Directive 128/2009/EC (an obligatory statute law for EU Member States) in mind we tested compatibility of our entomopathogens with diflubenzuron. Since the repeated use of diflubenzuron in pine forests may pose some hazard to beneficial insects and may lead to emergence of resistant insect populations [18], there is a need to explore other control measures in order to develop an integrated management approach. Incorporating two insect growth regulators such as buprofezin or diflubenzuron into fungal growth media affected neither fungal germination nor fungal growth (unpublished data). However, native B. bassiana (LIB1) isolate in combination with diflubenzuron significantly reduced population of $1^{\text {st }}$ instar larvae of whiteflies under greenhouse conditions suggesting additive effect. These results are in agreement with those of Jin et al. [47] who reported that incorporating $30.8 \mathrm{~g}$ buprofezin ha-1 into the fungal sprays elevated brown planthopper field control by 30\%. To achieve better control of aphids and whiteflies by entomopathogenic fungi, further screening of virulent isolates is necessary. Moreover, development of formulations and application methods for potentially effective fungi are also necessary, because the humidity and temperature of a greenhouse or field air is not always favourable for fungal infection when compared with the optimized laboratory conditions.

In conclusion, this study reports of a presence of $M$. anisopliae and $B$. bassiana fungi in Lebanese soils and their effectiveness against aphids and whitefly control. These isolates can be developed as biocontrol agents for the greenhouse use against whiteflies. Also, the authors would like to report of $E$. formosa parasitizing $76 \%$ of $M$. persicae aphids under natural and $100 \%$ under controlled conditions suggesting that this parasitoid may not be a strict specialist.

\section{Acknowledgement}

The authors thank the National Council for Scientific Research for financial support, Lebanese University for allowing using their facilities and Dr. Samih El-Hajj for help with statistical analysis. 


\section{References}

[1] Schepers A. (1989) Elsevier Science Publishers, Netherlands.

[2] Foster S.P., Denholm I., Harling G. and Devonshire A.L. (1998) Bull. of Entomol. Res., 88, 27-130.

[3] Harrington R. and van Emden H.F. (2007) CABI Publishing, UK.

[4] Copping L.G. (2004) British Crop Protection Council, UK.

[5] Zimmermann G. (2007) Biocont. Sci. Technol., 17,879-920.

[6] Butt T.M., Ibrahim L., Ball B.V. and Clark S.J. (1994) Biocontrol Sci. Techn., 4, 207-214.

[7] Butt T.M., Ibrahim L., Clark S.G. and Beckett A. (1995) Mycol. Res., 99, 945-950.

[8] Meyling N.V. and Eilenberg J. (2006) Biol. Control, 43, 274-287.

[9] Jung H.S., Lee H.B., Kim K. and Lee E.Y. (2006) Korean J. Mycol., 34,112-118.

[10] Yeo H., Pell J.K., Alderson P.G., Clark S.J. and Pye B.J. (2003) Pest. Manag. Sci. 59,156 165.

[11] Quesada M.E., Maranhao E.A.A., García P.V. and Alvarez C.S. (2006) Biol. Control, 36, 274-287.

[12] Bruck D.J. (2005) Biol. Control, 32,155-163.

[13] Casadevall A. and Pirofski L. (2001) J. Infect. Diseas. 184,337-344.

[14] Ibrahim L., Butt T.M. and Jenkinson P. (2002) Mycol. Res., 106, 705-715.

[15] Shah F.A., Wang C.S. and Butt T.M. (2005) FEMS Microbiol. Let. 251, 259-266.

[16] Roy H.E., Brown P.M.J., Rothery P., Ware R.L. and Majerus M.E.N. (2008) BioControl, 53, 265-276.

[17] Brown H.A. and Khan A. (2009) J. Biopesticides, 2,199-203.

[18] Nemer N. and Nasr J. (2004) Biocontrol News Inf., $14,9 \mathrm{~N}: 11 \mathrm{~N}$.

[19] Rath A.C., Koen T.B. and Yip H.Y. (1992) Mycol. Res., 96, 378-384.

[20] Veen K.H. and Ferron P. (1996) J. Invertebr. Pathol. 8,268-269.

[21] IMI (1993) The International Mycological Institute Series of Descriptions of Pathogenic Fungi and Bacteria. CAB International, UK.

[22] Humber R.A. (1998) Entomopathogenic Fungal Identification Keys. APS/ESA Workshop.

[23] Abbott W.S. (1925) J. Econ. Entomol., 18, 265-267.

[24] SAS Institute (1990) SAS/STAT User's Guide. Version 6, 4th edn. SAS Institute, Cary, NC

[25] Weibull W. (1951) J. App. Mechanics, 18, 293-297.
[26] Tulloch M. (1976) Trans. Brit. Mycol. Soci. 66,407411.

[27] Hesketh H., Alderson P.G., Pye B.J. and Pell J.K. (2008) Biol. Control, 46, 242-255.

[28] Shah, P.A. and Pell J.K. (2003) Appl. Microbiol. Biotechnol. 61,413-423.

[29] De Faria M. R. and Wraight S.P. (2007) Biol. Control, 43, 237-256.

[30] Eilenberg J., Hajek A. and Lomer C. (2001) BioControl, 46,387-400.

[31] Abdo C., Nemer N., Nemer G., Abou Jawdah Y., Atamian H. and Kawar N.S. (2008) BioControl, 53, 341-352.

[32] Hermandez-Crespo P. and Santiago-Alvarez P. (1997) Biocontrol Sci. Techn., 7, 353-363.

[33] Duggar B.M. (1989) Fungus diseases of plants. Agro Botanical Publisher, India.

[34] Shah P.A., Godonou I., Gbongboni C.and Lomer C.J.(1994) Biocontrol Sci. Techn., 4, 331-341.

[35] Shin T.Y., Choi J.B., Bae S.M., Koo H.M. and Woo S.D. (2010) Int. J. Indudt. Entomol., 20, 7-12.

[36] Fargues J.F. and Roberts P.H. (1983) Can. J. Microbiol., 29,576-583.

[37] Zayed A. and Zebitz C.P.W. (1997) MitteilungDeutschen Gesellschaft fur allgerneine und Angewandte Entomologie 11, 579-582.

[38] Shan L.T. and Feng M.G. (2010) Pest. Manag. Sci., 66, 669-675.

[39] Blackburn M.B., Gelman D.B. and Hu J.S. (2002) Biochem. Physiol., 51, 13-26.

[40] Askary H. and Brodeur J. (1999) J. Invert. Pathol., 73,129-132.

[41] Ceryngier P. and Hodek I. (1996) Enemies of Coccinellidae. In: Hodek I and Honk A (eds) Ecology of Coccinellidae. Kluwer Academic Publishers, Dordrecht

[42] Frensen J.J. and van Lenteren (1994) Entomol. Exp. Appl., 71, 235-243.

[43] Pell J.K., Pluke R., Clark S.J., Kenward M.G. and Alderson P.G. (1997) J. Invert. Pathol. 69, 261-268.

[44] Roy H.E., Pell J.K., Clarks S.J. and Alderson P.G. (1998) J. Invert. Pathol. 71, 236-247.

[45] Roy H.E., Alderson P.G. and Pell J.K. (2001) Biocontr. Sci. Technol., 11, 99-110.

[46] Ormond E.L, Thomas A.P.M, Pell J.K., Freeman S.N. and Roy H.E. (2010) FEMS Microbiol. Ecol., 77, 229-237.

[47] Jin S-F., Feng M-G., Ying S-H., Mu W-J. and Chen J-Q. (2011) Pest. Manag. Sci., 67, 36-43.

Table 1 - Isolate number, species and origin of isolates of entomopathogenic fungi

\begin{tabular}{|l|l|l|l|}
\hline No & Species & Isolated from & Location \\
\hline LIM1 & M. anisopliae & Soil (private garden) & Dalhoun, Central Lebanon \\
\hline LIM2 & M. anisopliae & Soil (private garden) & Dalhoun, Central Lebanon \\
\hline LIM3 & M. anisopliae & Soil (private garden) & Dalhoun, Central Lebanon \\
\hline V2751 & M. anisopliae & Carpocapsa pomonella, Austria & University of Wales, Swansea, UK \\
\hline LIB1 & B. bassiana & Soil, fallow land & Wadi Dalhoun, Central Lebanon \\
\hline Botanigarda & B. bassiana & Active ingredient of BotaniGard® (Laverlam) & University of Wales, Swansea, UK \\
\hline
\end{tabular}

a from Dr. T.M. Butt, University of Wales, Swansea, UK 
Table -2 - Pathogenicity of entomopathogenic fungi to M. persicae ( 2 and 7 days post inoculation at $23 \pm 2^{\circ} \mathrm{C}$ )

\begin{tabular}{|l|l|l|l|l|l|l|}
\hline Strains & Fungal spp & Mortality, \%a & Mycosis, \%b & Mortality, \% & Mycosis, \% L $^{\mathbf{d}}$ & LT $_{50}{ }^{\mathrm{e}}$ \\
\hline LIM1 & M.anisopliae & $53.6 \pm 4.1 \mathrm{a}^{\mathrm{f}}$ & $45.0 \pm 3.9 \mathrm{a}$ & $100.00 \pm 0.0 \mathrm{a}$ & $82.2 \pm 2.8 \mathrm{c}$ & $1.8(0.04) \mathrm{a}$ \\
\hline LIM2 & M.anisopliae & $53.1 \pm 1.7 \mathrm{a}$ & $44.3 \pm 4.4 \mathrm{a}$ & $100.00 \pm 0.0 \mathrm{a}$ & $78.9 \pm 2.7 \mathrm{c}$ & $1.9(0.04) \mathrm{a}$ \\
\hline LIM3 & M.anisopliae & $57.3 \pm 4.2 \mathrm{a}$ & $42.1 \pm 4.3 \mathrm{a}$ & $100.00 \pm 0.0 \mathrm{a}$ & $80.3 \pm 2.3 \mathrm{c}$ & $1.2(0.08) \mathrm{b}$ \\
\hline LIB1 & B. bassiana & $80.0 \pm 0.0 \mathrm{~b}$ & $52.5 \pm 1.9 \mathrm{~b}$ & $100.00 \pm 0.0 \mathrm{a}$ & $77.3 \pm 1.3 \mathrm{c}$ & $1.1(0.04) \mathrm{b}$ \\
\hline V275 & M.anisopliae & $80.6 \pm 0.3 \mathrm{~b}$ & $32.2 \pm 2.9 \mathrm{a}$ & $100.00 \pm 0.0 \mathrm{a}$ & $44.6 \pm 5.3 \mathrm{a}$ & $1.4(0.04) \mathrm{b}$ \\
\hline BotaniGard & B. bassiana & $51.8 \pm 7.2 \mathrm{a}$ & $31.0 \pm 3.4 \mathrm{a}$ & $100.00 \pm 0.0 \mathrm{a}$ & $62.2 \pm 3.3 \mathrm{~b}$ & $2.0(0.08) \mathrm{a}$ \\
\hline
\end{tabular}

a Mean \% mortality \pm SE, 2 days post inoculation

${ }^{b}$ Mean $\%$ mycosed aphid cadavers \pm SE, 2 days post inoculation

c Mean \% mortality \pm SE, 7 days post inoculation.

a Mean \% mycosed aphid cadavers \pm SE, 7 days post inoculation

e $L T_{50}$, time in days when $50 \%$ of M. persicae individuals were dead. Numbers in parenthesis are SE

${ }^{f}$ Means followed by the same letter do not differ significantly at $P<0.05$

Note- Control mortalities did not exceed more than 3\% 7 days post-inoculation. Dead control aphids did not develop any mycosis on their cadavers

Table-3 - Pathogenicity of entomopathogenic fungi for $B$. tabaci 1 st instar larvae (7 days post inoculation at $23 \pm 2^{\circ} \mathrm{C}$ )

\begin{tabular}{|l|l|l|l|}
\hline Strain & Fungal spp & Mortality, $\%^{\mathbf{a}}$ & $\mathbf{L T}_{50^{\mathbf{b}}}$ \\
\hline LIM1 & M. anisopliae & $62.8 \pm 1.2 \mathrm{a}^{\mathrm{c}}$ & $5.3(0.09) \mathrm{c}$ \\
\hline LIM2 & M. anisopliae & $70.3 \pm 1.6 \mathrm{~b}$ & $5.2(0.08) \mathrm{c}$ \\
\hline LIM3 & M. anisopliae & $63.7 \pm 1.2 \mathrm{ab}$ & $5.6(0.1) \mathrm{cd}$ \\
\hline LIB1 & B. bassiana & $88.0 \pm 1.6 \mathrm{c}$ & $4.5(0.08) \mathrm{b}$ \\
\hline V275 & M. anisopliae & $87.2 \pm 2.3 \mathrm{c}$ & $6.0(0.1) \mathrm{d}$ \\
\hline BotaniGard & B. bassiana & $96.5 \pm 1.4 \mathrm{~d}$ & $3.4(0.2) \mathrm{a}$ \\
\hline
\end{tabular}

a Mean \% mortality \pm SE, 7 days post inoculation.

${ }^{b} L T_{50}$, time in days when $50 \%$ of $B$. tabaci 1 st instar larvae individuals were dead. Number in parentheses are SE

c Means followed by the same letter do not differ significantly at $P<0.05$ level

Note. There were no mortalities in controls

Table-4 - Pathogenicity of native M. anisopliae and B. bassiana against M. persicae and B. tabaci 1st instar at different conidial concentrations, 9 days post treatment

\begin{tabular}{|c|c|c|c|c|c|c|}
\hline $\begin{array}{l}\text { Host and } \\
\text { isolate }\end{array}$ & $\begin{array}{l}\mathrm{LC}_{50^{\mathrm{a}}} \text { (log } \quad 10 \\
\text { scale) } \\
\text { conidia } \mathrm{ml}^{-1}\end{array}$ & $\begin{array}{l}10^{4} \text { conidia } \\
\mathrm{ml}^{-1} \\
\mathrm{LT}_{50}(\mathrm{SE})^{\mathrm{b}}\end{array}$ & $\begin{array}{l}10^{5} \text { conidia } \mathrm{ml}^{-} \\
{ }^{1} \mathrm{LT}_{50}(\mathrm{SE})\end{array}$ & $\begin{array}{l}10^{6} \text { conidia } \\
\mathrm{ml}^{-1} \\
\mathrm{LT}_{50}(\mathrm{SE})\end{array}$ & $\begin{array}{l}\text { 107conidia } \\
\mathrm{ml}^{-1} \\
\mathrm{LT}_{50}(\mathrm{SE})\end{array}$ & $\begin{array}{l}10^{8} \text { conidia } \\
\mathrm{ml}^{-1} \\
\mathrm{LT}_{50}(\mathrm{SE})\end{array}$ \\
\hline \multicolumn{7}{|l|}{ M. persicae } \\
\hline LIM1 & $4.75(4.23-5.10) b^{c}$ & $-d$ & $6.8(1.23) a$ & $3.41(0.66) \mathrm{a}$ & $1.63(0.43) a$ & $0.67(0.25) \mathrm{a}$ \\
\hline LIB1 & 3.88 (3.42-4.33)a & $8.8(0.97)$ & $5.6(1.08) a$ & $3.89(0.47) a$ & $1.49(0.41) \mathrm{a}$ & $0.88(0.21) a$ \\
\hline \multicolumn{7}{|l|}{ B. tabaci } \\
\hline LIM1 & $5.78(5.23-6.21) b$ & - & $7.8(1.01) b$ & $6.13(1.31) b$ & $4.31(0.58) b$ & $2.49(0.31) b$ \\
\hline LIB1 & $4.12(3.85-4.67) \mathrm{a}$ & - & $6.3(1.33) a$ & $5.45(0.98) \mathrm{a}$ & $3.06(0.41) \mathrm{a}$ & $1.57(0.13) \mathrm{a}$ \\
\hline
\end{tabular}

a $L C_{50}$, conidial concentration (log 10 scale) at which $50 \%$ of insect individuals were dead. Numbers in parentheses are $95 \%$ fiducial limits

${ }^{b} L T_{50}$, time in days when $50 \%$ of insect individuals were dead. Number in parentheses are SE

c Means followed by the same letter do not differ significantly at $P<0.05$ level

$d$ - $L T_{50}$ values were higher than 9 days and thus not included in statistical analysis 


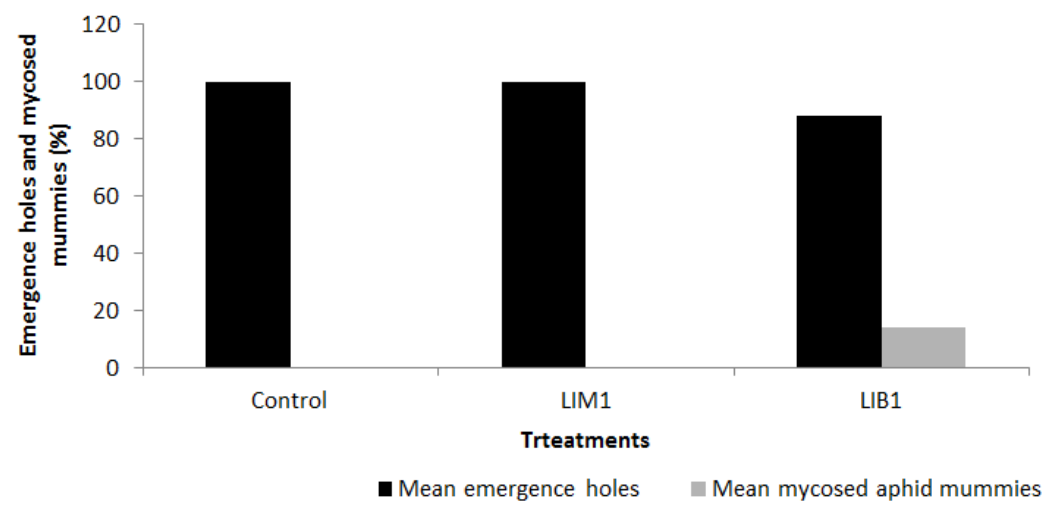

Fig. 1 - Percentage of emergence holes (black bars) and percentage of mycosed aphids (grey bars) mummified by E. Formosa, 9 days post treatment with M. anisopliae (LIM1) and B. bassiana (LIB1). Error bars are corresponding to SE. Different letters indicate significant differences at $P<0.05$ level

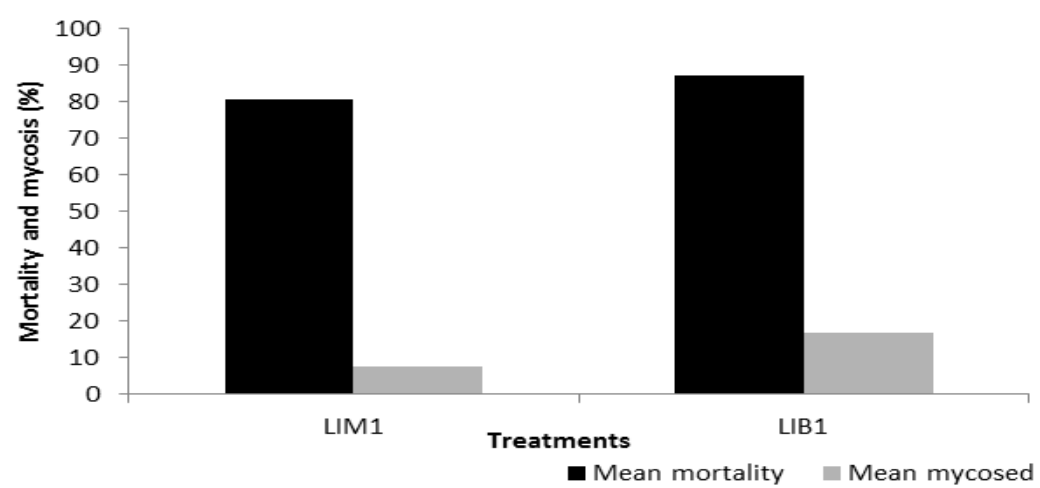

Fig. 2 - Percentage mean mortality and mycosis of $C$. montrouzieri, 9 days post treatment with M. anisopliae (LIM1 (black bars)) and $B$. bassiana (LIB1(grey bars)). Values were corrected for controls using Abbott's formula. Error bars are corresponding to SE. Different letters indicate significant differences at $P<0.05$ level

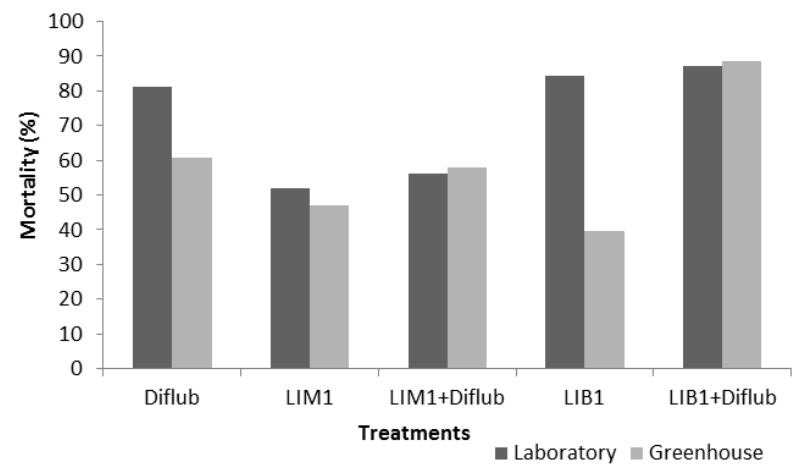

Fig. 3 - Efficacy of M. anisopliae LIM1 and B. bassiana LIB1 combined with diflubenzuron on 1st instar larvae of whiteflies under laboratory (black bars) and greenhouse conditions (gray bars),14 days post treatment. Values corrected for controls by Abbott's formula. Error bars are corresponding to SE. Different letters indicate significant differences at $P<0.05$ level 